Basic Health Sciences

Poster

Abstract ID: 136

\title{
Infectious agents and immune responses in schizophrenia: A case control study
}

Mohammed Imad Al-Deen Mustafa Mahmud | Berjees Rafi | Umeed Ali Khan | Hassan Mohamed El Hady

Kulliyyah of Medicine, International Islamic University Malaysia

Introduction: Exact causal mechanism of schizophrenia is still unknown; however, genetic and environmental factors are implicated in disease aetiology. The aim of the study is to determine the association of infectious agents cytomegalovirus and T.gondii along with immune cytokines IL-2, IL- 6 and IFN- $\gamma$ with schizophrenia. Methods: Ninety subjects participated in the study, 45 were patients diagnosed with schizophrenia, and the other 45 were a healthy control group. Qualitative and quantitative enzyme immunoassays were used for detection of antibodies and quantitation of cytokines respectively in subjects' sera. Results: Both patients and control groups had similar CMV seroprevalence of $93.3 \%$ (42/45). Prevalence of anti T. gondii lgG antibodies were $53.3 \%$ and $64.4 \%$ among schizophrenic patients and controls respectively. No statistically significant difference was observed between patients and controls $(p>0.05)$. A significant difference $(p<0.005)$ between mean serum Interleukin-2 levels in patients $(14.7 \mathrm{pg} / \mathrm{mL})$ and controls $(33.5$ $\mathrm{pg} / \mathrm{mL})$ was observed. No statistically significant difference $(\mathrm{p}>0.05)$ was found between the median IQR serum Interleukin-6 levels of patients $(4.3 \mathrm{pg} / \mathrm{mL})$ and controls $(3.1$ $\mathrm{pg} / \mathrm{mL})$. There was a significant difference $(\mathrm{p}<0.001)$ in median IQR serum IFN $-\gamma$ levels between patients $(0.8 \mathrm{pg} / \mathrm{mL})$ and the control group $(4.9 \mathrm{pg} / \mathrm{mL})$. Conclusions: No significant differences between schizophrenic patients and healthy controls with regard to previous infections with cytomegalovirus or T.gondii were observed. While significantly higher levels of proinflammatory cytokines IL- 6 and IFN - $\gamma$ among controls than patients might be an indication of weaker than normal immune responses in schizophrenic patients.

KEYWORDS: schizophrenia, cytomegalovirus, toxoplasma, IgG, IgM, IL-6, IFN - Y 